\title{
Production of exopolysaccharides by the cyanobacterium Anabaena sp. BTA992 and application as bioflocculants
}

\author{
Romi Khangembam ${ }^{1 *}$, Onkar Nath Tiwari ${ }^{1}$, Mohan Chandra Kalita ${ }^{2}$ \\ ${ }^{1}$ National Repository for Cyanobacteria and Microgreen Algae (Freshwater), Microbial Resources Division, Institute of Bioresources and Sustainable \\ Development, (A National Institute of DBT, Govt. of India), Takyelpat, Imphal-795001, Manipur, India. ${ }^{2}$ Department of Biotechnology, Gauhati \\ University, Guwahati, Assam, India.
}

\section{ARTICLE INFO}

\section{Article history:}

Received on: 03/12/2015

Revised on: 28/12/2015

Accepted on: 16/01/2016

Available online: 19/02/2016

Key words:

Cyanobacteria,

exopolysaccharide,

flocculants, 16S rRNA

typing, $\mathrm{pH}$.

\begin{abstract}
Bioflocculant exopolysaccharide (EPS) production by ten (10) cyanobacterial strains comprising of five (05) heterocystous and five (05) non-heterocystous strains during their photoautotrophic growth was investigated. Highest level of EPS was produced by Anabaena sp. BTA992 among the investigated strains with high flocculation capacity. The cyanobacterial EPS consisted of soluble protein and polysaccharide that included substantial amounts of neutral sugars and uronic acid. The flocculant bound a cationic dye, alcian blue, indicating it to be polyanionic. EPS production was maximum during stationary growth phase and late phase of growth at $\mathrm{pH}$ 8.5. The strain was identified by $16 \mathrm{~S}$ rRNA typing and GenBank accession number was obtained as KJ830950. The investigation revealed that this Anabaena sp. could be a potential candidate for the commercial EPS production and might be utilized in applications as an alternative to synthetic flocculants.
\end{abstract}

\section{INTRODUCTION}

Cyanobacteria also known as blue green algae are a group of extraordinary diverse gram negative prokaryotes that originated 3.5 billion years ago. Their diversity ranges from unicellular to multicellular, coccoid to branched filaments, nearly colourless to intensely pigmented autotrophic to heterotrophic, psychrophilic to thermophilic, acidophilic to alkylophilic, planktonic to barophilic, freshwater to marine including hypersaline [1]. Microbial polysaccharides are attracting increasing interest for their potential applications in the food, cosmetic and pharmaceutical industries, competing with other natural polysaccharides obtained from plants and macroalgae [2]. Besides the standard applications of microbial EPSs as food coatings, emulsifying and gelling agents, flocculants, hydrating agents etc., the specially anionic nature of cyanobacterial polysaccharides make them interesting for biomedical applications, since sulfated polysaccharides have been demonstrated to possess inhibitory properties against various types of viruses and tumours [3-4] and in the field of

* Corresponding Author

E-mail: bittu.khangembam@gmail.com

Mobile no.: +919856203698 bioremediation since they can be used to remove toxic metals from polluted waters [5]. Moreover, in recent years, interest in the exploitation of valuable EPSs has been increasing for various industrial applications and the attention towards polysaccharide producing bacteria and cyanobacteria has greatly increased. EPSs are regarded as abundant source of structurally diverse polysaccharides, some of which may possess unique properties for special applications. In the present work the effect of two main culture factors i.e. light and $\mathrm{pH}$ on bioflocculant exopolysaccharides nitrogen fixing strain of the cyanobacterium Anabaena was studied.

\section{MATERIALS AND METHODS}

\subsection{Cyanobacterial culture conditions}

For this study, ten (10) fast-growing cyanobacterial strains were obtained from the National repository for cyanobacteria and microgreen algae (freshwater) of the Institute of Bioresources and Sustainable Development, Imphal, Manipur, India. All these strains were originally isolated from Indo-Burma biodiversity hotspots of north-eastern India falling under Indian territory. Cultivation was conducted in 250-ml Erlenmeyer flasks containing $100 \mathrm{ml}$ of BG11 medium [6]. 
The nitrate component of the medium was excluded for culturing heterocystous strains except when otherwise indicated, but was included for culturing all non-heterocystous strains. Batch cultures were prepared for characterization and optimization of bioflocculant exopolysaccharide production by cyanobacteria by the methods followed Tiwari et al. [7].

\subsection{Exopolysaccharide assay and flocculating activity test}

Two paper pins were allowed to settle at the bottom of the flasks and kept in a magnetic stirrer for $15 \mathrm{~min}$ for maceration, to separate the capsular slime polysaccharide for, the culture. Soluble EPS released in the medium was separated from intact cyanobacteria by centrifugation of cultures at $6600 \mathrm{X} \mathrm{g}$ at $15^{\circ} \mathrm{C}$ for $20 \mathrm{~min}$ (Centrifuge $5430 \mathrm{R}$, Eppendorf, Germany). The supernatant was concentrated to one-fourth of its original volume by evaporating in a hot-air oven (Universal Oven - 143, Narang Scientific Works, India) at $60^{\circ} \mathrm{C}$ for $10-12 \mathrm{~h}$. The EPS in the concentrated liquid was precipitated by the gradual addition of three volumes of cold ethanol and was then kept at $4^{\circ} \mathrm{C}$ overnight [8]. The precipitate was washed twice by suspension in cold ethanol, followed by centrifugation. The gel-like pellet obtained after the final centrifugation was dialyzed against 5 volumes of distilled water overnight at room temperature. The dialysate was then dried at $60^{\circ} \mathrm{C}$ to a constant weight. Bioflocculant capacity of the EPS extract was determined by a little modification of Alcian blue binding assay [9].

Flocculating activity was calculated as:

Flocculating activity $=[(\mathrm{B}-\mathrm{A}) / \mathrm{B}] \mathrm{X} 100 \%$, where $\mathrm{A}$ and $\mathrm{B}$ are the absorbance values of sample and control respectively, at $610 \mathrm{~nm}$.

Chemical components of the dialyzed EPS from the two strains were analysed. Total neutral sugar content was estimated by Anthrone method [10]. Total soluble protein was measured according to Hebert et al. [11]. Uronic acid content from the hydrolysed EPS was determined spectrophotometrically using the Carbazole method [12].

\subsection{Strain Identification}

Genomic DNA was extracted by a modified xanthogenate method [13]. PCR amplification of 16S rRNA gene sequences was performed using the universal forward primer 536F and reverse primer 1488R [14]. All PCR reactions were performed in a total volume of $50 \mu \mathrm{l}$ containing $200 \mu \mathrm{M}$ dNTPs, $0.3 \mu \mathrm{M}$ of each primer, $1 \times$ Taq buffer, $5 \mathrm{U}$ Taq DNA polymerase, and $2 \mu \mathrm{l}$ of genomic DNA. Amplification was performed in a thermal cycler (Mastercycler gradient, Eppendorf, Germany). After an initial denaturation at $95{ }^{\circ} \mathrm{C}$ for $5 \mathrm{~min}$, the mixture was subjected to 28 cycles including final denaturation at $95{ }^{\circ} \mathrm{C}$ for $1 \mathrm{~min}$, annealing at $55^{\circ} \mathrm{C}$ for $1 \mathrm{~min}$, and final extension at $72{ }^{\circ} \mathrm{C}$ for $1 \mathrm{~min}$. The PCR product was detected with standard agarose gel electrophoresis (Elchrom Scientific GEPS 200/2000, Switzerland), and quantification of PCR product was done with BioSpectrometer (Eppendorf, Germany). Partial 16S rRNA gene sequence was obtained and retrieved accession number from NCBI GenBank.

\subsection{Time course assay of EPS production and flocculation at different $\mathbf{p H}$}

The effect of initial $\mathrm{pH}$ of the production medium was also assessed in the range of (5.0-10.0) using $0.1 \mathrm{M} \mathrm{H}_{2} \mathrm{SO}_{4}$ and $\mathrm{NaOH}$, at different growth phases. Experiments were carried out in triplicates to reproduce the experiment and standard deviations were also obtained.

\section{RESULTS AND DISCUSSION}

\subsection{EPS characterization and flocculating activity}

All 10 of the examined cyanobacterial strains were screened for EPS production by separating and recovering large molecules from the supernatant of cultures. Anabaena sp. BTA992 produced the highest level of exopolysaccharide $(1.27 \pm 0.09 \mathrm{mg}$ $\mathrm{ml}^{-1}$ ). The total amount of EPS includes the released polysaccharides in the medium and capsular or slime polysaccharides. The total EPS and flocculating activity of the EPS producing strains are indicated in table 1. The biochemical composition of EPS for the highest producing strain, Anabaena sp. BTA992 is indicated in figure 1. The strain utilized in this study produced large amounts of EPS relative to the amounts reported for other cyanobacteria, reaching $1.7 \mathrm{mg} \mathrm{ml}^{-1}$ of culture. The values observed in the present study were among the highest reported for any EPS-producing cyanobacterium or EPS-producing lactic acid bacteria [15].

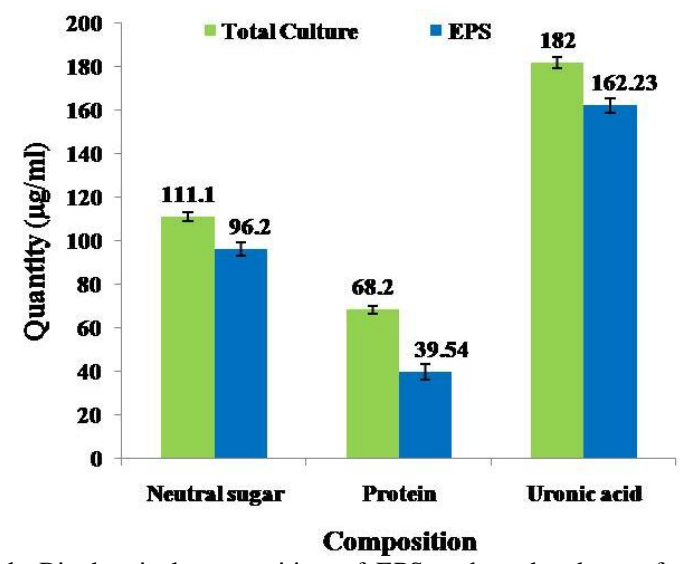

Fig. 1: Biochemical composition of EPS and total culture of Anabaena sp. BTA992 (with standard deviations, $\mathrm{n}=3$ )

A chemical analysis of the strain with highest EPS production demonstrated the presence of neutral sugars, soluble proteins and uronic acid. A diverse range of polysaccharides, with various sugars, uronic acids and proteins, have been observed previously in cyanobacterial EPS [16]. Analysis of EPS production by the unicellular cyanobacterium, Cyanothece sp., demonstrated a considerable quantity of EPS that contained various sugars and uronic acid [17]. The presence of uronic acids and sulfate groups confer on cyanobacterial EPS, a negative charge that contributes to efficient sequestering of cations, specifically those of heavy metals [18]. The strain produced bioflocculant within the $\mathrm{pH}$ range (7-9) as depicted in figure 2. The optimal activity of $88 \%$ was found at 
$\mathrm{pH}$ 8.5, after which flocculating activity declined, indicating that the isolate was slightly alkalophilic.

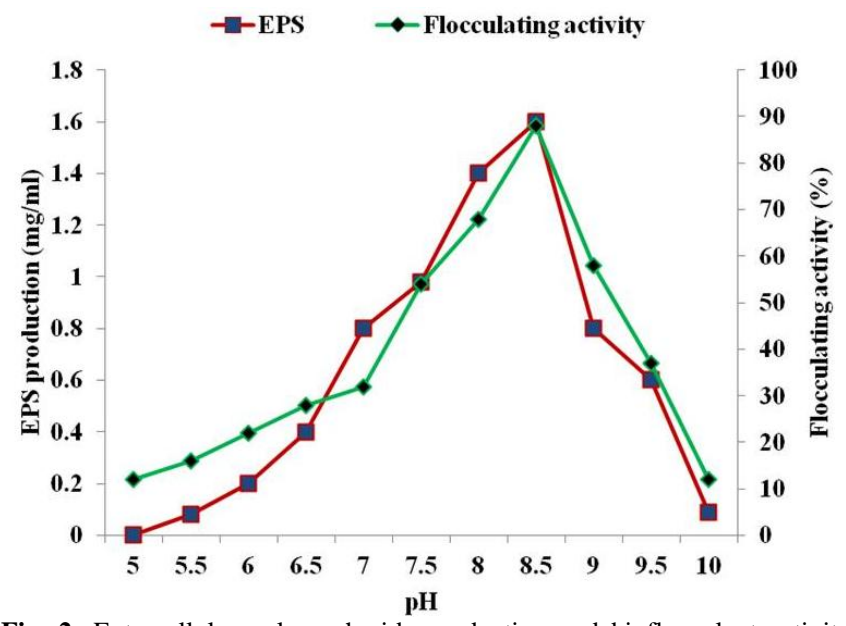

Fig. 2: Extracellular polysaccharide production and bioflocculant activity of Anabaena sp. BTA992 in different $\mathrm{pH}$ range.

It also demonstrated that, the effectiveness of the bioflocculant was at a wide range. However, the flocculant production and activity efficiency slightly reduced at highly acidic medium $(\mathrm{pH}<6)$ and highly alkaline medium $(\mathrm{pH}>9)$. Environmental conditions such as light intensity, temperature, culture medium, growth stage or nutrient availability affect the composition and quantity of EPS [19]; [20]. pH of the culture medium is important for cell growth and EPS production, perhaps relating to its influences on nutrient solubility and uptake, enzymatic activity, cell membrane morphology, byproduct formation and redox reactions [21-25], The flocculating activity of MMF1 isolated from the screening medium was $82.9 \%$ [26] which can be compared with present studied strains. For the industrial applications of p-KG03, as the bioflocculant agent, pKG03 showed that more than $90 \%$ of the flocculating activity in kaolin suspension occurred at concentrations of $0.5 \mathrm{mg} \mathrm{l}^{-1}$ with the maximum at $1.0 \mathrm{mg} \mathrm{l}^{-1}$ [27].

Table 1: Total EPS production and flocculating activity of the ten EPSproducing strains.

\begin{tabular}{llll}
\hline SN & \multicolumn{1}{c}{ Name of the strains } & $\begin{array}{c}\text { EPS } \\
\text { production } \\
(\mathbf{m g} / \mathbf{m l})\end{array}$ & $\begin{array}{c}\text { Bioflocculant } \\
\text { activity }\end{array}$ \\
\hline 1 & Anabaena sp. BTA 992 & $1.27 \pm 0.09$ & $74.63 \%$ \\
2 & Anabaena circinalis BTA129 & $1.14 \pm 0.07$ & $72.04 \%$ \\
3 & Nostoc hatei BTA12 & $1.02 \pm 0.05$ & $62.03 \%$ \\
4 & Calothrix marchica BTA46 & $1.03 \pm 0.00$ & $52.08 \%$ \\
5 & Nostoc epplipsosporum BTA685 & $0.86 \pm 0.02$ & $52.03 \%$ \\
6 & Oscillatoria sp. BTA239 & $0.92 \pm 0.05$ & $42.03 \%$ \\
7 & Phormidium fragile BTA02 & $0.52 \pm 0.07$ & $16.41 \%$ \\
8 & Plectonema radiosum BTA32 & $0.54 \pm 0.02$ & $12.03 \%$ \\
9 & Phormidium sp. BTA254 & $0.56 \pm 0.03$ & $7.62 \%$ \\
10 & Phormidium tenue BTA261 & $0.42 \pm 0.05$ & $6.46 \%$ \\
\hline
\end{tabular}

\section{CONCLUSIONS}

The flocculating efficiency and chemical properties of the compound bioflocculant produced by Anabaena sp. BTA992 was investigated. The bioflocculant maintained wide $\mathrm{pH}$ range producing flocculating activity with a maximum peak of $88 \%$ at $\mathrm{pH}$ 8.5. The bioflocculant was found to be a glycoprotein with the presence of uronic acid which was responsible for the flocculation mechanism. Nonetheless, the high flocculation activity observed indicates prospects towards industrial applications, and in addition, further studies on process conditions are needed for the prospect of large-scale production.

\section{ACKNOWLEDGEMENTS}

Authors are thankful to the Director, IBSD, Imphal, Manipur, India for providing laboratory facilities and Department of Biotechnology, Government of India for financial assistance vide grant no: BT/218/NE/TBP/2011.

\section{REFERENCES}

1. Thajuddin N, Subramanian G. Cyanobacterial biodiversity and potential applications in biotechnology. Current Science. 2005; 89: 47 57.

2. Sutherland IW. Novel and established applications of microbial polysaccharides. Trends in Biotechnology. 1998; 16:41-46.

3. Itoh $\mathrm{H}$, Noda $\mathrm{H}$, Amano $\mathrm{H}$, Zhuaug $\mathrm{C}$, Mizuno $\mathrm{T}$, Ito $\mathrm{H}$. Antitumor activity and immunological properties of marine algal polysaccharides, specially fucoidan, prepared from Sargassum thunbergii of Phaeophyceae. Anti cancer Research. 1993; 13, 2045-2052.

4. Herrero A, Muro-Pastor A, Flores E. Nitrogen control in cyanobacteria. Journal of Bacteriology. 2001; 183, 411-425.

5. Shah V, Ray A, Garg N, Madamwar D. Characterization of the extracellular polysaccharide produced by a marine cyanobacterium, Cyanothece sp. ATCC 51142, and its exploitation toward metal removal from solutions. Current Microbiology. 2000; 40, 274-278.

6. Stanier RY, Kunisawa R, Mandel M, Cohen-Baziere G. Purification and properties of unicellular blue-green algae (order Chroococcales). Bacteriology Reviews. 1971; 35: 171-205.

7. Tiwari ON, Romi KH, Minerva SH, Aribam SS, Gunapati O, Jerry JB Characterization and Optimization of Bioflocculant Exopolysaccharide Production by Cyanobacteria Nostoc sp. BTA97 and Anabaena sp. BTA990 in Culture Conditions. Applied Biochemistry and Biotechnology. 2015; 176(7): 1950-1963.

8. Klock JH, Weiland A, Seifert R, Michaeli W. Extracellular polymeric substances (EPS) from cyanobacterial mats: characterization and isolation method optimization. Marine Biology. 2007; 152: 1077 1085.

9. Bar-Or Y, Shilo M. Characterization of macromolecular flocculants produced by Phormidium sp. strain J and by Anabaenopsis circularis PCCC 6720. Applied and Environmental Microbiology. 1987; 53: 2226-2230.

10. Spiro RG. Analysis of sugars found in glycoproteins. Method in Enzymology. 1966; 8: 3-26.

11. Herbert TD, Phipps PJ, Strange RE. Chemical analysis of microbial cells. In: Methods of Microbiology (Morris, J.R. Ribbon, D.W. editors), 1971; 209-234, Academic Press, New York.

12. Galambos JT. The reaction of carbazole with carbohydrates. 1. Effect of borate and sulfamate on the carbazole color of sugars. Analytical Biochemistry. 1967; 19: 119-132.

13. Avijeet SO, Oinam G, Singh KO, Tiwari ON. Isolation of fresh water cyanobacterial DNA of north east India by modified xanthogenate method. International Journal of Research in BioSciences. 2013; 2(2): 75-82.

14. Nubel U, Garcia-Pichel F, Muyzer G. PCR primers to amplify $16 \mathrm{~S}$ rRNA gene from cyanobacteria. Applied and Environmental Microbiology. 1997; 63(8): 3327-3332. 
15. Raus Madieldo P, De Los Reyes Gavilan CG. Invited review: methods for the screening, isolation and characterization of exopolysaccharides produced by lactic acid bacteria. Journal of Dairy Science. 2005; 88: 843-856.

16. Sutherland IW. Structure-function relationships in microbial exopolysaccharides. Biotechnology Advances. 1994; 12: 393-448.

17. Ohki K, Nguyen QT, Yoshikawa S, Kanesaki Y, Okajima M, Kaneko T, Tran HT. Exopolysaccharide production by a unicellular freshwater cyanobacterium Cyanothece sp. isolated in a rice field of Vietnam. Journal of Applied Phycology. 2014; 26(1): 265-272.

18. De Philippis R, Colica G, Micheletti E. Exopolysaccharide-producing cyanobacteria in heavy metal removal from water: molecular basis and practical applicability of the biosorption process. Applied Microbiology and Biotechnology. 2011; 92: 697-708.

19. West TP. Effect of carbon source on polysaccharide production by alginate-entrapped Aureobasidium pullulans ATCC 42023 cells. Journal of Basic Microbiology. 2011; 51: 673-677.

20. Parikh A, Madamwar D. Partial characterization of extracellular polysaccharides from cyanobacteria. Bioresource Technology. 2006; 97: 1822-1827.

21. De Philippis R, Margheri MC, Pelosi E, Ventura S. Exopolysaccharide production by a unicellular cyanobacterium isolated from a hypersaline habitat. Journal of Applied Phycology. 1993; 5: 387-394.

22. Khattar JS, Singh DP, Jindal N, Kaur N, Singh Y, Rahi P, Gulati A. Isolation and characterization of exopolysaccharides produced by the cyanobacterium Limnothrix redekei PUPCCC 116. Applied Biochemistry and Biotechnology. 2010; 162: 1327-1338.
23. Tischer RG, Davis EB. The effect of various nitrogen sources upon the production of extracellular polysaccharide by the blue-green alga Anabaena flosaquae A-37. Journal of Experimental Botany. 1971; 22: 546-551.

24. Li P, Harding SE, Liu Z. Cyanobacterial Exoplysaccharides: their nature and potential biotechnological applications. Biotechnology and Genetic Engineering. 2001; 18: 375-404.

25. Singh S, Das S. Screening, production, optimization and characterization of cyanobacterial polysaccharide. World Journal of Microbiology and Biotechnology. 2011; 27: 1971-1980.

26. Kumar AS, Mody K, Jha B. Bacterial exopolysaccharides: a perception. Journal of Basic Microbiology. 2007; 47: 103-117.

27. De Philippis R, Vincenzini M. Exocellular polysaccharides from cyanobacteria and their possible applications. FEMS Microbiology Review. 1998; 22: 151-175.

\section{How to cite this article:}

Khangembam R, Tiwari ON, Kalita MC. Production of exopolysaccharides by the cyanobacterium Anabaena sp. BTA992 and application as bioflocculants. J App Biol Biotech. 2016; 4 (01): 008-011. DOI: 10.7324/JABB.2016.40102 